University of New Hampshire

University of New Hampshire Scholars' Repository

$1-2014$

\title{
Weather, climate, and the economy: Explaining risk perceptions of global warming, 2001-10
}

\author{
Wanyun Shao \\ Louisiana State University at Baton Rouge \\ Barry D. Keim \\ Louisiana State University \\ James C. Garand \\ Louisiana State University at Baton Rouge \\ Lawrence C. Hamilton \\ University of New Hampshire, lawrence.hamilton@unh.edu
}

Follow this and additional works at: https://scholars.unh.edu/soc_facpub

Part of the Sociology Commons

\section{Recommended Citation}

Shao, W., Keim, B.D., Garand, J.C., Hamilton, L.C. Weather, climate, and the economy: Explaining risk perceptions of global warming, 2001-10. (2014) Weather, Climate, and Society, 6 (1), pp. 119-134.

This Article is brought to you for free and open access by the Sociology at University of New Hampshire Scholars' Repository. It has been accepted for inclusion in Sociology Scholarship by an authorized administrator of University of New Hampshire Scholars' Repository. For more information, please contact Scholarly.Communication@unh.edu. 


\title{
Weather, Climate, and the Economy: Explaining Risk Perceptions of Global Warming, 2001-10*
}

\author{
WANYUN SHAO \\ Department of Geography and Anthropology, Louisiana State University, Baton Rouge, Louisiana \\ BARRY D. KEIM \\ Louisiana Office of State Climatology and Department of Geography and Anthropology, Louisiana State \\ University, Baton Rouge, Louisiana \\ JAMES C. GARAND \\ Department of Political Science, Louisiana State University, Baton Rouge, Louisiana \\ LAWRENCE C. HAMILTON \\ Department of Sociology, University of New Hampshire, Durham, New Hampshire
}

(Manuscript received 28 March 2013, in final form 26 August 2013)

\begin{abstract}
Two series of national survey datasets (2001-10), supplemented with monthly temperature and precipitation data and unemployment data, are used to examine how weather and climate, economic performance, and individuals' sociodemographic backgrounds and political orientations affect public perceptions of global warming. Consistent with previous studies, political orientations play a key role in determining public perceptions of global warming. Democrats and liberals are more likely than Republicans and conservatives to see global warming as an immediate and serious problem. Sociodemographic characteristics are also shown to be significant factors, with young people, women, and racial minorities likely to show higher concern about global warming than their counterparts. Moreover, individuals with lower income and higher levels of education tend to be more concerned about global warming. Net of these factors, summer temperature trends over the past 10 years, among other weather and climate measures, are shown to have consistently positive effects on public perceptions of global warming. This suggests that individuals who have experienced increasing summer heat are most likely to perceive immediate impacts and severity of global warming. Surprisingly, macroeconomic conditions-represented by the unemployment rate at the county level—do not appear to influence public perceptions of global warming.
\end{abstract}

\section{Introduction}

Despite decades of efforts by scientists to warn the public about the perils of global warming (e.g., Tegart et al. 1990; Watson et al. 1995; McCarthy et al. 2001; Parry et al. 2007), there is still no public consensus on its

\footnotetext{
* Supplemental information related to this paper is available at the Journals Online website: http://dx.doi.org/10.1175/WCAS-D13-00029.s1.

Corresponding author address: Wanyun Shao, 450 Laurel Street, Suite 1200, P.O. Box 44027, Baton Rouge, LA 70804-4027.

E-mail: abby.shao@la.gov
}

cause, existence, and impact (Nisbet and Myers 2007; Pew Research Center 2007, 2012). According to the scholarly literature, perceptions of global warming in the United States are affected by many variables, particularly political orientation such as party identification and political ideology (Dunlap et al. 2001; Dunlap and McCright 2008; McCright and Dunlap 2011a), race and gender (Leiserowitz 2006; Malka et al. 2009; McCright 2009; McCright and Dunlap 2011b; Kellstedt et al. 2008), age (Kellstedt et al. 2008; Krosnick et al. 2006; Malka et al. 2009), income (Hamilton and Keim 2009; McCright and Dunlap 2011a), education (Malka et al. 2009; McCright and Dunlap 2011a), and macroeconomic conditions (Kahn and Kotchen 2010). McCright and Dunlap (2011a) 
also provide additional sources through an extensive summary of the literature addressing social and political variables related to perceptions of global warming. In addition, there is a growing body of literature that has examined the effects of weather and climate on these perceptions. For example, public perceptions of global warming have been found to be linked to personal observation of local weather (Borick and Rabe 2010; Howe et al. 2013; Krosnick et al. 2006; Li et al. 2011; Myers et al. 2013), actual short-term weather fluctuations (Egan and Mullin 2012; Hamilton and Stampone 2013), long-term temperature change (Hamilton and Keim 2009), and weather extremes (Leiserowitz et al. 2012). However, questions still remain regarding the effects of local weather and climate on perceptions of global warming. In this paper, we attempt to take the research of perceptions of global warming to another level through the analysis of two series of national survey datasets, climatic data from the United States Historical Climate Network, and county-level unemployment data.

Both sets of surveys used in this study - the Pew Research Center for the People and the Press Polls and CBS News/New York Times polls-ask the same (the former series) or similarly worded (the latter series) survey questions about global warming. Each series of surveys also includes the same group of sociodemographic variables and political orientation variables measured repeatedly over time. We merge both sets of survey data with climate and unemployment data. We analyze each survey individually, and we then pool the surveys into two groups and conduct cross-sectional analyses to examine how the social and political variables (including age, gender, education, income, party identification, political ideology, race, and religious service attendance), weather and climate, and local economic conditions affect public perceptions of global warming. By pooling the data, we increase the sample size and temporal breadth of our analysis over that of previous studies. Our analyses represent a comprehensive effort to understand American risk perceptions of global warming in the first decade of the twenty-first century by integrating national survey data with place-specific indicators of weather, climate, and unemployment conditions.

Our objective is to explore relationships among demographic attributes, political orientations, weather and climate, the unemployment rate, and public perceptions of global warming in both individual years and for data pooled across a decade, from 2001 to 2010. In addition, we adopt a comprehensive set of weather and climate variables (including 10 different measures) to capture the effects of both short-term weather fluctuations and long-term climate trends. From these analyses, we aim to examine whether specific measures of local weather and climate are related to heightened risk perceptions of global warming.

\section{Data and methods}

\section{a. Data}

The survey data for this analysis come from two sources: CBS News/New York Times polls and Pew Research Center for the People and the Press Polls. For more details on surveys used in this analysis, see our supplemental material (available online at http://dx.doi.org/10.1175/ WCAS-D-13-00029.s1). The CBS News/New York Times polls relating to global warming come from the Interuniversity Consortium for Political and Social Research (ICPSR). These data consist of surveys conducted between June 2001 and August 2010. The CBS News and CBS News/New York Times surveys include similarly worded questions relating to the impact of global warming. The first dependent variable is derived from the following question:

"Do you think global warming is an environmental problem that is causing a serious impact now, or do you think the impact of global warming won't happen until sometime in the future, or do you think global warming won't have a serious impact at all?"

In addition, the Pew Research Center for the People and the Press Polls relating to global warming consist of six surveys including those conducted from June 2006 to October 2010. These surveys all ask the same question: "In your view, is global warming a very serious problem, somewhat serious, not too serious, or not a problem?"

The primary focus of this article is public perceptions of global warming based on these two questions. The CBS News/New York Times and the Pew Research Center surveys both include the same set of sociodemographic and political orientation variables, although there are differences in wording that prevent us from pooling surveys across these two polling organizations. The CBS News/New York Times poll series include gender, race, age, education, income, party identification, and ideology, while the Pew survey series has religious service attendance in addition to the other variables. The geographic codes provided by the seven CBS datasets are Federal Information Processing Standard (FIPS) county and state codes, while the six Pew surveys provide both zip codes and FIPS county and state codes. This permits us to merge contextual data including climate and unemployment data with the survey data.

We suggest that there are two aspects of individuals' risk perceptions as they relate to global warming. Global 
warming immediacy, which is measured in the CBS News/New York Times series, introduces a temporal element and involves individuals' perceptions of the time horizon for the occurrence of problems associated with global warming. In other words, are global warming and its associated risks here in the present, or are they something that will occur in the long-term future or not at all? Global warming severity, which is measured in the Pew series, involves individuals' perceptions of how serious or severe the problem of global warming is to humankind. In other words, is global warming a problem? If so, how severe a problem is it? These two concepts represent two separate dimensions of how individuals perceive the risks associated with global warming. Ideally, we would like to have measures of both concepts in the same dataset, but unfortunately our measures of these concepts are found only in separate surveys. However, we make the conceptual argument-untested in this paperthat these two dimensions are related, insofar as individuals who perceive that global warming is a serious problem and who perceive that it is in the present or in the near future will be most likely to be motivated to support actions to alleviate the anthropogenic determinants of global warming.

We supplement these survey data with long-term climate trends represented by temperature and precipitation trends over the past 10 years prior to the interview date, and short-term weather fluctuations represented by the departure from normal temperature/precipitation measured in standard deviation units over the month prior to the interview date. A more detailed description of these data and the variables that are derived from these data can be found below.

Furthermore, we supplement the survey data with unemployment rate data for the month prior to the interview date. We also combine the CBS surveys and Pew surveys into two pooled samples, respectively, and this permits us to estimate models of global warming perceptions over multiple surveys. Because all the individual surveys have different numbers of respondents, respondents in smaller surveys cannot be counted collectively as much as those respondents in larger surveys. Therefore, we use sampling weights based on the inverse of the sample size proportion of the total sample size for each survey to equalize the contribution of each survey because of the varying numbers of respondents across surveys. The result is that the weighted sample sizes for each survey are identical.

\section{b. Dependent variable}

Public perceptions of global warming are the primary focus of this paper. The merged data for the first part of our analysis come from seven CBS surveys conducted from 2001 to 2010 . While the questions relating to the expected impacts of global warming are similar, there is variation in the wording across the surveys. We are able to combine responses to create a comparable scale across all seven surveys, and in the end we are able to measure the first dependent variable, global warming immediacy, in each survey on a scale from 0 (no impact) to 2 (impact now). For more details on our approach to creating a consistent measure, see the supplemental material.

The pooled data for the second part of the analysis come from the six Pew surveys. The question wording is consistent across all of these surveys, which provide four responses about the seriousness of global warming: "very serious," "somewhat serious," "not too serious," and "not a problem." We code the second dependent variable, global warming severity, on a scale ranging from 0 (not a problem) to 3 (very serious).

\section{c. Independent variables}

\section{1) DEMOGRAPHIC CHARACTERISTICS}

We include age, education, income, gender, and race (black and Hispanic) in the first set of analyses that use the CBS series data. We include these variables and add religious service attendance in the second set of analyses of the Pew series data. The response categories to most relevant items on these two sets of survey data are somewhat different. Therefore, the corresponding responses we create based on each item are mostly different.

Specifically, for both analyses, we measure respondents' age in years, ranging from 18 to 99 years. For the first set of analyses that use the CBS series data, we measure education from 1 (respondent has not completed high school) to 5 (respondent has earned a postgraduate degree). We measure income ranging from 1 ("less than $\$ 15,000 ")$ to 5 ("more than $\$ 75,000 ")$. For the second set of analyses that use the Pew series data, we code education on a scale from 1 (none, or grade 1-8) to 7 (postgraduate training or professional schooling after college), while we measure income on a scale ranging from 1 (less than $\$ 10,000)$ to $9(\$ 150,000$ or more). The effect of age on public perceptions of global warming is usually found to be negative, suggesting that older individuals tend to show lower levels of concern for this issue (Hamilton 2012; Kellstedt et al. 2008; Krosnick et al. 2006; Malka et al. 2009; McCright and Dunlap 2011b). The effect of income on perceptions of global warming has a mixed record in the literature. Previous research demonstrates that income has a negative effect on public perceptions of climate change (Hamilton and Keim 2009) and concern for this issue (McCright and Dunlap 2011b), although Hamilton (2008) shows that higher levels of income are associated 
with greater concern for some impacts of global warming. Here, we speculate that older people with less education and less income are less likely to perceive global warming as an urgent issue, or as a serious problem.

In addition, we posit that the public perception of global warming is influenced by race and gender. The risk assessment literature has identified the "white male" effect, which indicates that racial minorities and women are more sensitive to, and therefore are more concerned about, risks because of their comparative vulnerability (Finucane et al. 2000; Marshall 2004). The white male effect has also been well documented in the literature on perceptions of global warming (Leiserowitz 2006; Malka et al. 2009; McCright 2009; McCright and Dunlap 2011b). Thus, we create three binary variables to represent black respondents ("black" $=1$; "other" $=0$ ), Hispanic respondents ("Hispanic" = 1 ; "other" $=0$ ), and gender ("women" $=1$; "men" $=0$ ) for both analyses. We hypothesize that the coefficients for these three variables are positive in predicting risk perception of global warming.

Finally, for the second set of analyses that use the Pew series data, we include religious services attendance in our models. This variable is measured on a scale ranging from 0 (never attend services) to 5 (more than once a week). Attending religious services has been found to have negative effects on public perceptions of climate change (Hamilton and Keim 2009). Thus, we posit that individuals who attend religious services more often are less likely to believe global warming is a serious problem.

\section{2) Political ORIENTATions}

Party identification and ideology have been shown to be important indicators of perceptions of global warming (Dunlap et al. 2001; Dunlap and McCright 2008; McCright and Dunlap 2011a; Pew Research Center 2006). As for the analyses that use the CBS series data, we measure ideology on a three-point scale, ranging from 0 (liberal) to 2 (conservative). Party identification is also measured on a three-point scale, ranging from 0 (Democrat) to 2 (Republican). We hypothesize that people who are conservative and are Republicans are less likely to perceive that global warming is an immediate problem. As for the analyses that use Pew series data, ideology is on a scale ranging from 0 (very liberal) to 4 (very conservative). We measure party identification on a scale, ranging from 0 (Democrat) to 4 (Republican). The implications associated with societal acceptance of global warming as an immediate and serious problem are multifaceted. One of the key implications is that to mitigate the effects of global warming, large-scale involvement of government will be required. Compared to liberals, conservatives tend to favor individual freedom in the economic sphere and private property rights over collective rights, as well as free market over governmental intervention (McCright and Dunlap 2011a). Dunlap and McCright (2008) note an increasingly wide gap between Republicans and Democrats on their views on climate change over the past decade, with an increasing proportion of Democrats accepting the occurrence of global warming and severity of this issue as opposed to a declining trend among Republicans. Therefore, we speculate that individuals who are more liberal and are Democrats are more likely to view global warming as an immediate and serious problem.

\section{d. Contextual variables}

\section{1) Weather AND Climate}

In this paper, we refer to weather as that which has occurred over the recent month relative to the surveys. We use the term climate to describe all time periods longer than a month. Climate and weather data are from the United States Historical Climatology Network (USHCN) monthly temperature and precipitation dataset (Karl et al. 1990). The USHCN provides a highquality, error-controlled dataset of basic daily and monthly meteorological/climatological variables from $1218 \mathrm{ob}-$ serving stations across the contiguous United States (http://cdiac.ornl.gov/epubs/ndp/ushcn/background.html). Using monthly temperature and precipitation data from USHCN, we create four seasonal temperature and four seasonal precipitation trends including winter (December-February), spring (March-May), summer (June-August), and fall (September-November) trends over the past 10 years prior to the survey dates. These variables represent the unstandardized regression coefficients from models that depict temperature or precipitation as a function of a yearly time counter variable, and therefore capture linear trends of temperature or precipitation over time. The selection of time frames for trends of $5,10,20$, or 30 years' duration is without firm theoretical foundation. The decision to select the 10-yr trend over other somewhat shorter or longer time periods is based on the consideration that although people tend to have short memories, they are also more likely to find environmental conditions salient if they are maintained over a reasonable period of time. Moreover, in earlier work we estimated a series of models using trends calculated over different time frames and ascertained that the 10 -yr time frame generated results that were most consistent with the data (W. Shao et al. 2013, unpublished manuscript). Hence we use a 10 -yr period to represent climate trends facing society that are recent enough to be remembered but long enough to be salient. We are aware that the number of observations (i.e., 10 data points per weather station) used to generate our trend estimates is 
small, but arguably the slope provides the best estimates of the trends in temperature and precipitation for the most recent period of climate affecting the public.

In addition, we include two weather measures to capture short-term weather fluctuations. These two measures are temperature and precipitation departure from normal (DNT and DNP, respectively) over the month prior to the survey date. To account for relative weather fluctuations in different regions, these departures are measured in standard deviation units. We take this approach because of the differences in weather and climate across the United States (e.g., North vs South, high altitude vs low altitude, coastal vs continental) and the varying conditions and ranges of variability between sites that result from these geographical variations. As such, we standardize the weather at each location by making all deviations relative to the climate at that specific site, all the while taking into account what is considered to be within a normal range. We calculate these two measures:

$$
\begin{aligned}
& \mathrm{DNT}_{i}=\left(\text { temperature }_{i} \text {-normal temperature }_{i}\right) / \text { standard deviation of temperature }(1981-2010), \\
& \mathrm{DNP}_{i}=\left(\text { precipitation }_{i} \text {-normal precipitation }\right) / \text { standard deviation of precipitation(1981-2010), }
\end{aligned}
$$

where $\mathrm{DNT}_{i}$ and $\mathrm{DNP}_{i}$ are respectively the local temperature and precipitation experienced by respondent $i$, temperature $_{i}$ and precipitation $_{i}$ are respondent $i$ 's local average temperature and monthly total precipitation over the month before his or her interview, normal temperature ${ }_{i}$ and normal precipitation $n_{i}$ are the normal average of monthly mean temperature and monthly total precipitation for that month, calculated over the period 1981-2010 (current normal period in climatology), and standard deviations of temperature and precipitation are the standard deviation of monthly mean temperature and monthly total precipitation calculated based on the monthly average over the period $1981-2010{ }^{1}$ Collinearity tests are conducted to ensure that multicollinearity is not present among the climate and weather variables, and an inspection of variance inflation factors (VIFs) reveals no evidence of multicollinearity.

The county and state FIPS codes provided by the CBS/New York Times series and zip codes provided by the Pew series data allow us to identify geographically each respondent. ${ }^{2}$ In ArcGIS, we match the layer of respondents' locations with the layer of USHCN weather station locations. By using the feature-that is, joining data from another layer based on spatial location - provided in

\footnotetext{
${ }^{1}$ The monthly data that we select depend on the date when each survey was conducted. When the survey was mainly conducted early in a particular month (i.e., before 15 th of that month), we extract the monthly average temperature and monthly total precipitation data on the month prior to the interview month. When the survey was conducted late on a particular month (i.e., after 20th of that month) or in the week between two months (i.e., from 28 April to 10 May), we extract the monthly average temperature and monthly total precipitation data for the current month.

${ }^{2} \mathrm{We}$ assume that each respondent is located at the centroid of each county or zip code area.
}

ArcGIS, we then identify the weather stations that are located closest to each respondent and use the monthly temperature and precipitation data from that station. Because there is an inadequate number of previous studies on the effects of local weather and climate on public opinion toward global warming, our hypotheses concerning all these long-term local weather and climate indicators are nondirectional except two-winter and summer temperature trends. Warming winter temperatures in snow country are associated with public perceptions of climate change (Hamilton and Keim 2009). In warmer parts of the country, people might be most aware of rising temperatures during the summer due to the greater discomfort from heat and the need for more air conditioning. Therefore, we hypothesize that the winter and summer temperature trends over the past decade are most likely have positive effects on risk perceptions of global warming.

The other contextual variable is the county unemployment rate. In his theory of human motivation, Maslow (1943) proposed hierarchies of prepotency, and arguably this provides an explanation for the competing relationship between concern for the environment and economy. Human motivation and human attention are limited resources. People tend to meet their basic physiological needs such as food, shelter, and economic stability before they turn their attention to aesthetic needs such as arts, entertainment, and environmental quality (Maslow 1943). The ability of individuals to meet these needs rests in no small part on their personal economic situation and the level of economic performance in a political or economic system. Hence it is possible that economic downturns will be perceived as inhibiting individuals' ability to meet their basic needs, while basic needs will be met more easily when the economy is doing well. Elliott et al. (1997) find that both individual and macroeconomic conditions have significant effects on public support for environmental spending. 
More recently, Hamilton et al. (2010) find a negative association between unemployment rate (county) and individuals' support for environmental rules. Similarly, Kahn and Kotchen (2010) find evidence to support the assertion that increases in the local unemployment rate (state and county) are associated with the decrease of concern for global warming, and therefore the decrease of intention to mitigate global warming. County-level data on unemployment rates are available from the U.S. Bureau of Labor and are merged by county with the survey data. We speculate that individuals who reside in counties with higher unemployment rates tend to be less concerned about global warming.

The inclusion of contextual variables raises some complications in regression analysis. Specifically, the error terms are not independent for observations that share the same weather station or are located in the same the county. There are two common approaches to address this issue: 1) a multilevel model (Rabe-Hesketh and Skrondal 2008) and 2) clustered standard errors (Primo et al. 2007). Unfortunately, the number of survey respondents in each clustered unit is insufficient to permit us to estimate a multilevel model. Given this, we estimate our models with clustered standard errors, which require fewer assumptions and less intensive computation compared to multilevel modeling (Primo et al. 2007).

\section{2) SURVEY FIXED EFFECTS}

There are seven surveys in the CBS series data and six surveys in the Pew series data. Therefore, for the CBS series data, we create dichotomous variables for each of six surveys, with the excluded survey representing the (excluded) reference survey. For the Pew series data, we create dichotomous variables for five surveys, with one being the reference survey. The purpose of doing so is to account for different mean values on the dependent variable across surveys, including those due to the small coding differences across surveys. For the sake of brevity the coefficients for these fixed effects variables are not reported in our statistical tables.

\section{3) INTERACTIONS}

Education has been found to have different effects on perceptions of global warming among Democrats and Republicans. While concern about global warming has been found to increase with the level of education among Democrats or liberals, these concerns decrease with the level of education among Republicans or conservatives (McCright and Dunlap 2011a; Hamilton and Keim 2009; Hamilton 2008, 2011, 2012; Pew Research Center 2007). We suggest that partisanship and ideology serve to filter information about global warming. Democrats and liberals are more likely to prioritize environmental concerns over economic concerns and are hence more likely to be receptive to information about global warming; on the other hand, Republicans and conservatives are more likely to prioritize economic concerns over environmental concerns and hence tend to exhibit higher resistance to information about global warming. To capture these effects, we include two interaction variables in both analyses. First, we include an interaction for education and party identification to capture the variable effects of education on perception of global warming across party lines. Following the findings from previous studies, we hypothesize that the effects of education on the dependent variable will be positive among Democrats and negative among Republicans, so we expect the coefficient for these interactions to be negative. Moreover, we posit that the relationship between education and perception of global warming will be positive among individuals who are liberal and negative among those who are conservative. Hence, we create an interaction variable for education and ideology; we expect that the coefficients for this variable will be negative.

A summary of the variables used in our two analyses can be found in Table 1 .

\section{Empirical analysis and results}

\section{a. Analysis I: Global warming immediacy}

We first model global warming immediacy as a function of a range of social variables, long-term climate trends, short-term weather variation, and unemployment rate. We initially estimate this model separately for each dataset of the CBS survey series, although our main focus is on the pooled surveys. We begin with the year-by-year models, the results for which are summarized in the first set of columns in Table 2. For the sake of brevity we report only the statistical significance of the coefficients, although the full results for each of the seven surveys can be found in supplemental material. The detailed presentation on the results can be found in the supplemental material. We present a brief report as follows.

To begin, we find that party identification and political ideology are the two most consistent predictor variables, with significant negative effects on global warming immediacy. Conservatives and Republicans are significantly less likely to perceive that global warming is causing impact now than liberals and Democrats. The results lend strong support to the assertion that political orientations play an essential role in determining public opinion toward global warming. Moreover, the coefficients for the various sociodemographic variables are less consistent. These demographic background results, including inconsistencies regarding income and race, broadly agree with those from other surveys as well. 
TABLE 1. Descriptive statistics for variables from the pooled CBS News and Pew surveys.

\begin{tabular}{|c|c|c|c|c|c|c|c|c|}
\hline \multirow[b]{2}{*}{ Variable } & \multicolumn{4}{|c|}{ CBS survey series (2001-10) } & \multicolumn{4}{|c|}{ Pew survey series (2006-10) } \\
\hline & Mean & Deviation & Minimum & Maximum & Mean & Deviation & Minimum & Maximum \\
\hline Global warming immediacy & 1.20 & 0.82 & 0 & 2 & - & - & - & - \\
\hline Global warming severity & - & - & - & - & 1.95 & 1.07 & 0 & 3 \\
\hline Party identification & 1.01 & 0.82 & 0 & 2 & 1.84 & 1.65 & 0 & 4 \\
\hline Ideology & 1.20 & 0.74 & 0 & 2 & 2.23 & 0.96 & 0 & 4 \\
\hline Age & 54.10 & 18.18 & 18 & 99 & 52.06 & 18.19 & 18 & 99 \\
\hline Gender & 0.60 & 0.49 & 0 & 1 & 0.52 & 0.50 & 0 & 1 \\
\hline Education & 3.23 & 1.18 & 1 & 5 & 4.74 & 1.62 & 1 & 7 \\
\hline Income & 3.53 & 1.30 & 1 & 5 & 5.20 & 2.36 & 1 & 9 \\
\hline Black & 0.07 & 0.25 & 0 & 1 & 0.10 & 0.31 & 0 & 1 \\
\hline Hispanic & 0.04 & 0.21 & 0 & 1 & 0.06 & 0.25 & 0 & 1 \\
\hline Religious service attendance & - & - & - & - & 2.72 & 1.61 & 0 & 5 \\
\hline Winter temperature trend & -1.62 & 1.97 & -9.14 & 5.89 & -1.26 & 2.00 & -10.34 & 5.94 \\
\hline Spring temperature trend & 0.32 & 2.05 & -5.65 & 8.34 & 0.17 & 1.57 & -5.41 & 6.03 \\
\hline Summer temperature trend & 0.53 & 1.38 & -6.38 & 6.42 & 0.60 & 1.32 & -6.34 & 7.11 \\
\hline Fall temperature trend & 0.11 & 1.29 & -4.38 & 7.33 & 0.43 & 1.39 & -4.38 & 6.55 \\
\hline Winter precipitation trend & -0.01 & 13.21 & -84.29 & 57.39 & 0.89 & 12.29 & -83.21 & 51.81 \\
\hline Spring precipitation trend & -1.77 & 10.92 & -40.75 & 44.84 & -0.08 & 15.16 & -122.82 & 141.63 \\
\hline Summer precipitation trend & 3.61 & 14.78 & -51.18 & 58.48 & 2.66 & 14.79 & -61.96 & 67.90 \\
\hline Fall precipitation trend & 2.30 & 15.51 & -56.90 & 49.28 & 2.49 & 15.01 & -56.90 & 51.11 \\
\hline $\begin{array}{l}\text { Average temperature } \\
\text { departure }\end{array}$ & 0.41 & 1.02 & -2.82 & 2.97 & 0.41 & 0.80 & -2.69 & 2.94 \\
\hline $\begin{array}{l}\text { Average precipitation } \\
\text { departure }\end{array}$ & -0.24 & 0.89 & -2.39 & 3.96 & -0.00 & 0.95 & -2.18 & 4.92 \\
\hline Unemployment rate & 6.67 & 3.24 & 1.60 & 23.90 & 7.04 & 2.98 & 1.40 & 31.80 \\
\hline
\end{tabular}

Among the weather and climate indicators, summer temperature trend over the past decade has the most consistent effect on global warming immediacy. The unemployment rate at the county level over the month prior to the interview date is not found to have any significant effects on global warming immediacy so we have no evidence from these data for the popular belief that concerns over unemployment preempt individuals' perceptions about global warming.

Fluctuations in the effects of some of these independent variables across surveys are not totally unexpected, particularly given the relatively smaller sample sizes for some of the surveys. We gain a better perspective and more confidence about overall effects of these variables by pooling the survey data together and then re-estimating our models to include a series of fixed-effect variables to account for survey-to-survey variation. In Table 3 we report the empirical results for models using the CBS survey series (models 1-3) and the Pew survey series (models 1-3).

In model 1 of Table 3 for the CBS survey series, we report the coefficients for the independent variables, but without the interaction variables. All of the social variables except race have significant effects on global warming immediacy. As the results from this model for the CBS survey series show, the observed effect of gender conforms to the findings from most studies of perceptions of global warming, with women significantly more likely to view global warming as causing immediate impact. Race represented by blacks and Hispanics are not significantly different than whites on this dependent variable. Moreover, the coefficient for education is positive, indicating that individuals with higher education tend to perceive that global warming has an immediate impact. On the other hand, the income variable has a negative effect on global warming immediacy. High-income individuals are less likely to perceive the immediacy of global warming. Finally, we find that older people are less likely to see that global warming is causing immediate impacts; it appears that younger individuals are more likely to be receptive to information about the immediate impact of global warming.

As for political orientation variables, the effects of party identification and ideology are significantly negative, indicating that Republicans (Democrats) and conservatives (liberals) are less (more) likely to see global warming causing immediate impact. Using results from model 1 in Table 3 for the CBS survey series and holding the values of all other independent variables constant at their means, we estimate predicted probabilities across the scales of party identification and political ideology. To demonstrate the effects of party and ideology on public perceptions of global warming, we present the predicted probabilities for the relationship between party and ideology, respectively, and three views toward 
TABLE 2. Summary of coefficients for survey-specific models of public risk perceptions. Note that coefficients that are in the expected direction (under directional hypotheses) and significant at the $0.05,0.01$, and 0.001 levels are denoted by one, two, and three asterisks, respectively. Additionally, for significant coefficients under non- or two-directional hypotheses, the direction is also reported by plus $(+)$ and minus (-) signs. The expected direction of the coefficients is reported in brackets.

\begin{tabular}{|c|c|c|c|c|c|c|c|c|c|c|c|c|c|}
\hline & \multicolumn{7}{|c|}{ CBS/New York Times surveys } & \multicolumn{6}{|c|}{ Pew Research Center surveys } \\
\hline & $6 / 01$ & $4 / 07$ & $10 / 07$ & $12 / 07$ & $2 / 09$ & $4 / 10$ & $8 / 10$ & $6 / 06$ & $1 / 07$ & $4 / 08$ & $5 / 09$ & $10 / 09$ & $10 / 10$ \\
\hline \multicolumn{14}{|c|}{ Demographic attributes } \\
\hline Age $[-]$ & & & $-* *$ & $-* *$ & & $-* *$ & $-*$ & & & & & $-*$ & $-* *$ \\
\hline Gender $[+]$ & & & $+* *$ & $+*$ & $+* * *$ & $+* * *$ & $+* * *$ & $+* * *$ & $+* * *$ & $+*$ & $+*$ & $+* * *$ & $+* * *$ \\
\hline Education $[+]$ & & & $+*$ & $+*$ & $+*$ & $+* *$ & $+* *$ & $+*$ & & $+*$ & $+*$ & & $+*$ \\
\hline Income $[-]$ & & & & & & & & $-* *$ & & $-*$ & $-*$ & $-* * *$ & \\
\hline Race: Black [+] & & & & & & & $+* *$ & & & & & & \\
\hline Race: Hispanic [+] & & & & & & & & $+*$ & & $+*$ & $+* * *$ & & \\
\hline $\begin{array}{l}\text { Religious service attendance } \\
{[-] \text { (Pew) }}\end{array}$ & & & & & & & & $-* *$ & $-* * *$ & & $-*$ & $-*$ & $-* *$ \\
\hline \multicolumn{14}{|c|}{ Political orientation } \\
\hline Partisan identification [-] & $-* * *$ & $-* * *$ & $-* * *$ & $-* * *$ & $-* * *$ & $-* * *$ & $-* * *$ & $-* * *$ & $-* * *$ & $-* * *$ & $-* * *$ & $-* * *$ & $-* * *$ \\
\hline $\begin{array}{l}\text { Liberal/conservative } \\
\text { ideology }[-]\end{array}$ & $-* *$ & $-* * *$ & $-* * *$ & $-* * *$ & $-* * *$ & $-* * *$ & $-* * *$ & $-* * *$ & $-* * *$ & $-* * *$ & $-* * *$ & $-* * *$ & $-* * *$ \\
\hline \multicolumn{14}{|c|}{ Contextual variables } \\
\hline \multicolumn{14}{|l|}{ Winter temperature trend $[+]$} \\
\hline \multicolumn{14}{|l|}{$\begin{array}{l}\text { Spring temperature trend } \\
{[+/-]}\end{array}$} \\
\hline Summer temperature trend $[+]$ & & $-*$ & & $+*$ & & $+*$ & & & $+*$ & & & $+* *$ & \\
\hline $\begin{array}{l}\text { Fall temperature trend }[+/-] \\
\text { Winter precipitation trend } \\
{[+/-]}\end{array}$ & & & & $+*$ & & & & & & & & & \\
\hline $\begin{array}{l}\text { Spring precipitation trend } \\
{[+/-]}\end{array}$ & & & & & $-*$ & & $+*$ & & & & & & \\
\hline \multicolumn{14}{|l|}{$\begin{array}{l}\text { Summer precipitation } \\
\text { trend }[+/-]\end{array}$} \\
\hline Fall precipitation trend $[+/-]$ & & & & $-*$ & & & & $+*$ & $+*$ & & & $+*$ & \\
\hline $\begin{array}{l}\text { Short-term temperature } \\
\text { fluctuation }[+/-]\end{array}$ & & & & $-* *$ & $+*$ & $+*$ & & & & & & & \\
\hline $\begin{array}{l}\text { Short-term precipitation } \\
\text { fluctuation }[+/-]\end{array}$ & & & & & & & & & $-*$ & $-* *$ & & & \\
\hline Unemployment [-] & & & & & & & & $-*$ & & & & & \\
\hline
\end{tabular}

global warming. Based on the probabilities presented in Fig. 1a, we find that, moving from 0 (Democrat) to 2 (Republican), the probability that individuals believe that "global warming is causing a serious impact now" decreases from $61 \%$ to $29 \%$, while the probability that one believes that "global warming won't have any serious impact at all" increases from $11 \%$ to $31 \%$. For the statement "global warming is causing a serious impact now," the probability that Democrats believe this is $61 \%$, compared to $29 \%$ for Republicans, while independents fall in between. For the statement "the impact of global warming won't happen until sometime in the future," the probability that Republicans believe this is $40 \%$, compared to $29 \%$ for Democrats. It appears that there is a consensus among Democrats that global warming is having an immediate impact, while Republicans are fairly equally divided among the three options.
Likewise, based on the probabilities presented in Fig. 1b, it appears that liberals and conservatives differ considerably in their views toward global warming. As one moves from 0 (liberal) to 2 (conservative), the probability that individuals believe that "global warming is causing serious impact now" decreases from $64 \%$ to $32 \%$, and the probability of believing "global warming won't have any serious impact at all" increases from $10 \%$ to $29 \%$. Liberals are more likely to believe that "global warming is causing a serious impact now" (64\%) while only $32 \%$ of conservatives hold that view. For the statement "the impact of global warming won't happen until sometime in the future," the probability that conservatives believe this is $38 \%$, compared to $27 \%$ for liberals, with moderates in between. Here again, there is a relative consensus among liberals about global warming immediacy, while conservatives are split among the three options. 


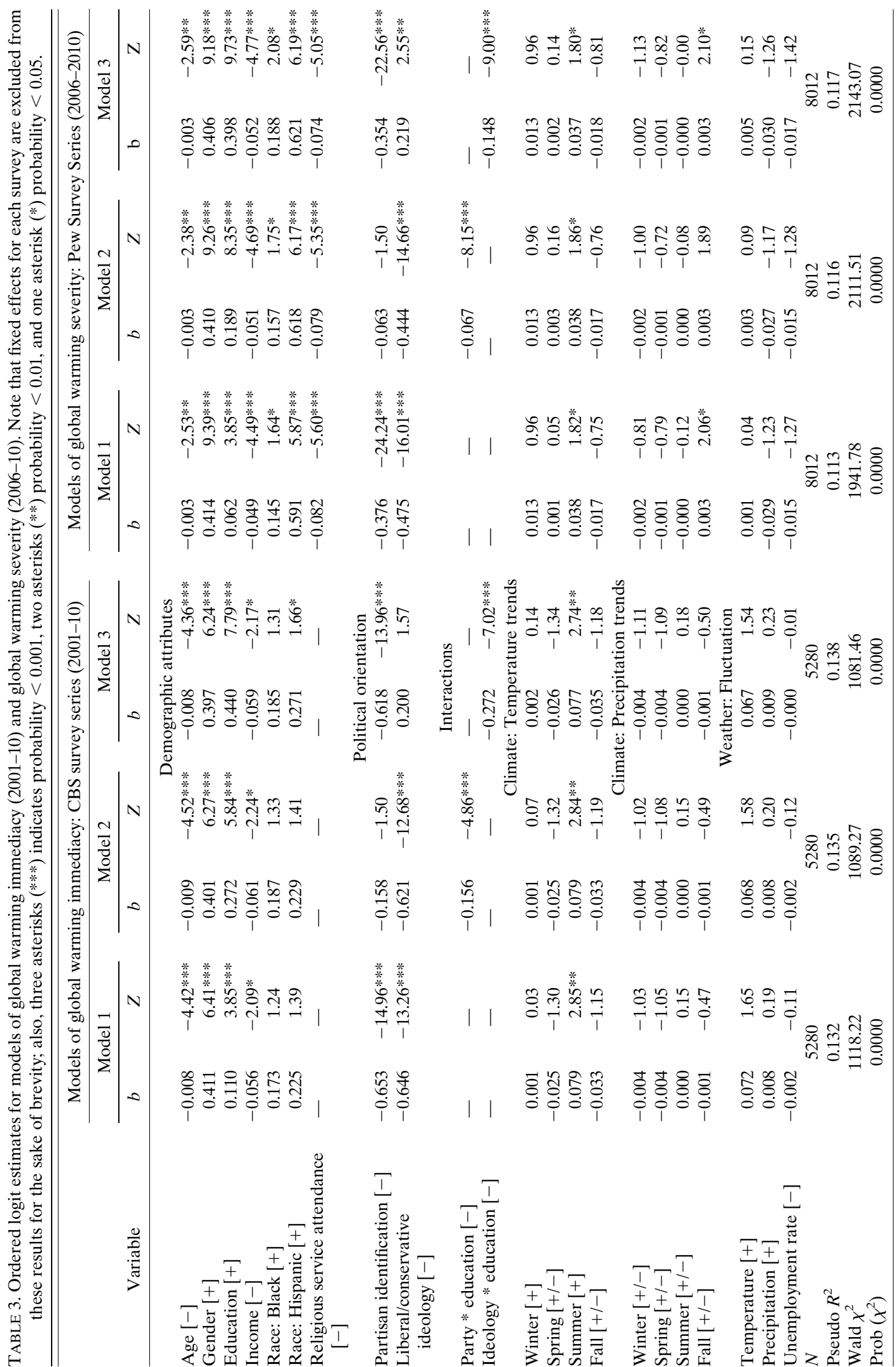



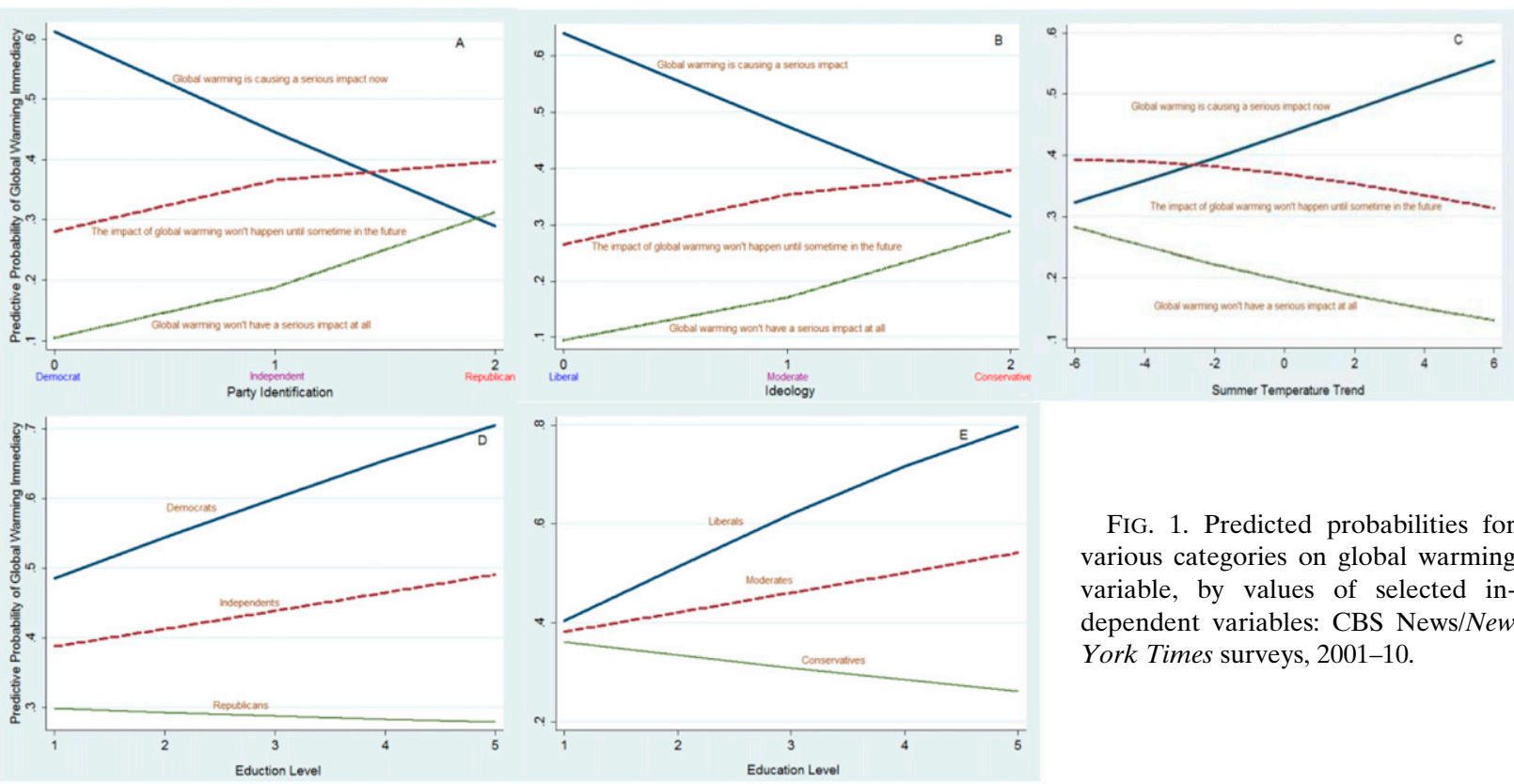

FIG. 1. Predicted probabilities for various categories on global warming variable, by values of selected independent variables: CBS News/New York Times surveys, 2001-10.

Among the weather and climate measures, we find that only one variable has significant effects on the dependent variable. The summer temperature trend over the past 10 years - indicating the magnitude of rising summer temperatures-exerts a positive effect on global warming immediacy, indicating that individuals who experience increasingly hot summers are more likely to believe global warming is having an immediate impact now.

To illustrate the effects of climate, in Fig. 1c we present predicted probabilities for the relationship between the temperature trend during the summer over the past 10 years and individuals' perceptions that "global warming is causing a serious impact now," "the impact of global warming won't happen until sometime in the future," and "global warming won't have a serious impact at all," controlling for the effects of all the other independent variables. As individuals' experience of summers moves from -6 (roughly the lowest point) to 6 (roughly the highest point) on the range of summer temperature trend, the probability that individuals believe that "global warming is having a serious impact now" increases from $32 \%$ to $55 \%$, while the probability that individuals believe that "global warming won't have a serious impact at all" decreases from $28 \%$ to $13 \%$. The probability that people believe "the impact of global warming won't happen until sometime in the future" decreases slightly from $39 \%$ to $32 \%$.

Surprisingly, the unemployment rate at the county level does not show any significant effect on the dependent variable either for individual data analyses or the pooled data analysis. This does not conform to previous research findings about the relationship between public support of the environment and the economy (Elliott et al. 1997; Hamilton et al. 2010; Kahn and Kotchen 2010), but this result might be due to the fact that the unemployment rate-a proxy for macroeconomic conditions-does not necessarily reflect personal economic conditions and individuals' subjective judgments of the economy. The local county-level economy does not appear to have a direct effect on how people think about global warming. Instead, personal economic conditions involving how an individual is doing economically (e.g., Is the person unemployed? Did the person's income increase or decrease in the past year?) might compete with local climate as a determinant of individuals perceptions of global warming. In addition, objective macroeconomic conditions do not necessarily translate into subjective assessment of economic conditions. For many individuals there is a gap between the reality of the economy and individuals' subjective judgments on the objective economy. Regrettably, a variable representing either personal economic conditions or an individual's subjective assessments of economic conditions is not included in this dataset.

In models 2 and 3 of Table 3 for the CBS survey series, we include all the independent variables from model 1 but also add two interactions for education with partisanship and ideology, respectively. The coefficients for the interaction for education and party identification and for the interaction for education and political ideology are both significant and in the expected direction. In Table 3, model 2 for the CBS survey series the 
coefficient for education is 0.272 , which represents the effect of education on public perceptions of global warming immediacy among Democrats (i.e., those for whom party identification equals 0 ). The coefficient for the interaction variable for party identification and education is -0.156 , indicating that the effects of education on the log-odds ratio of the dependent variable decreases 0.156 as party identification increases by one unit in the Republican direction. The effect of education for Republicans is -0.041 [i.e., $0.272+(2 \times-0.156)$ ], suggesting that education barely has any effects on global warming immediacy among Republicans. In other words, as education level increases, Democrats are more likely to view global warming as causing immediate impacts, while Republicans are slightly less likely to do so. To illustrate the interaction effects for partisanship and education in Fig. 1d, we present predicted probabilities for the relationship between education level and individuals' perceptions that "global warming is causing a serious impact now," broken down by Democrats, independents, and Republicans and controlling for the effects of other independent variables by holding them constant at their means. For Democrats with low education (i.e., not a high school graduate), the probability that they perceive "global warming is causing a serious impact now" is $48.5 \%$; this rises to a probability of $70.5 \%$ for Democrats with a high education level (i.e., postgraduate work or degree). On the other hand, the relationship between education level and perceptions of global warming impact is slightly negative for Republicans; the probability of perceiving that "global warming is causing serious impact now" decreases from $29.9 \%$ to $28 \%$ as education levels move from the lowest to highest value.

In model 3 of Table 3 for the CBS survey series we present estimates of similar interaction effects of education and political ideology on global warming immediacy. The coefficient for education $(b=0.440, Z=7.79)$ represents the effect of education for liberal identifiers (i.e., those for whom ideology equals 0). For liberals, there is a very strong positive effect of education on their perceptions of global warming. Meanwhile, the coefficient for the interaction for political ideology and education is negative and highly significant $(b=-0.272$, $Z=-7.02$ ), indicating that the effects of education on the log-odds ratio of the dependent variable decreases 0.272 as political ideology increases by one unit (i.e., as one moves from liberal toward conservative). In other words, as education level increases, liberals are more likely to perceive global warming immediacy while conservatives are less likely to do so. We calculate the education coefficient for conservatives as -0.104 [i.e., $0.440+(2 \times-0.272)]$, which indicates that conservatives with higher levels of education are less likely to view global warming immediacy. To illustrate the interaction effects for ideology and education in Fig. 1e, we present predicted probabilities for the relationship between education level and individuals' perceptions that "global warming is causing a serious impact now," estimated separately for liberals, moderates, and conservatives and controlling for other independent variables constant at their means. For liberals with low education levels (i.e., those who are not a high school graduate), the probability that they perceive "global warming is causing a serious impact now" is $40.4 \%$; this rises to a probability of $79.7 \%$ for liberals with a high education level (postgraduate work or degree). On the other hand, the relationship between education level and perceptions of global warming impact is moderately negative for conservatives; the probability of perceiving that "global warming is causing serious impact now" decreases from $36.2 \%$ to $26.2 \%$ as the education level moves from its lowest to highest value.

\section{b. Analysis II: Global warming severity}

In this section we discuss the determinants of global warming severity, but in this case we examine data from several Pew Center surveys conducted between June 2006 and October 2010. We begin by modeling global warming severity as a function of a range of social variables (now including church attendance), long-term climate trends, short-term weather variation, and unemployment rate for each dataset of the Pew survey series. Empirical results for the individual Pew surveys are presented in the second set of columns in Table 2. For more detailed discussion, see the supplemental material.

We find strong effects for most of the demographic and political predisposition variables on perceptions of global warming severity. With the exception of black racial status, there is evidence of demographic and political effects on the dependent variable. Local weather and climate variables-represented by different combinations of indicators-show significant effects throughout these years except in the May 2009 and October 2010 surveys. Finally, the unemployment rate at the county level only displays significant effects on global warming severity in the survey conducted in June 2006. This conforms to the results in the analysis of CBS News survey series.

In Table 3, we present results for models of global warming severity using data pooled across all six surveys. In model 1 for the Pew survey series we present the coefficients for the model estimated without the interaction variables. As one can see, all the sociodemographic variables have significant effects on 

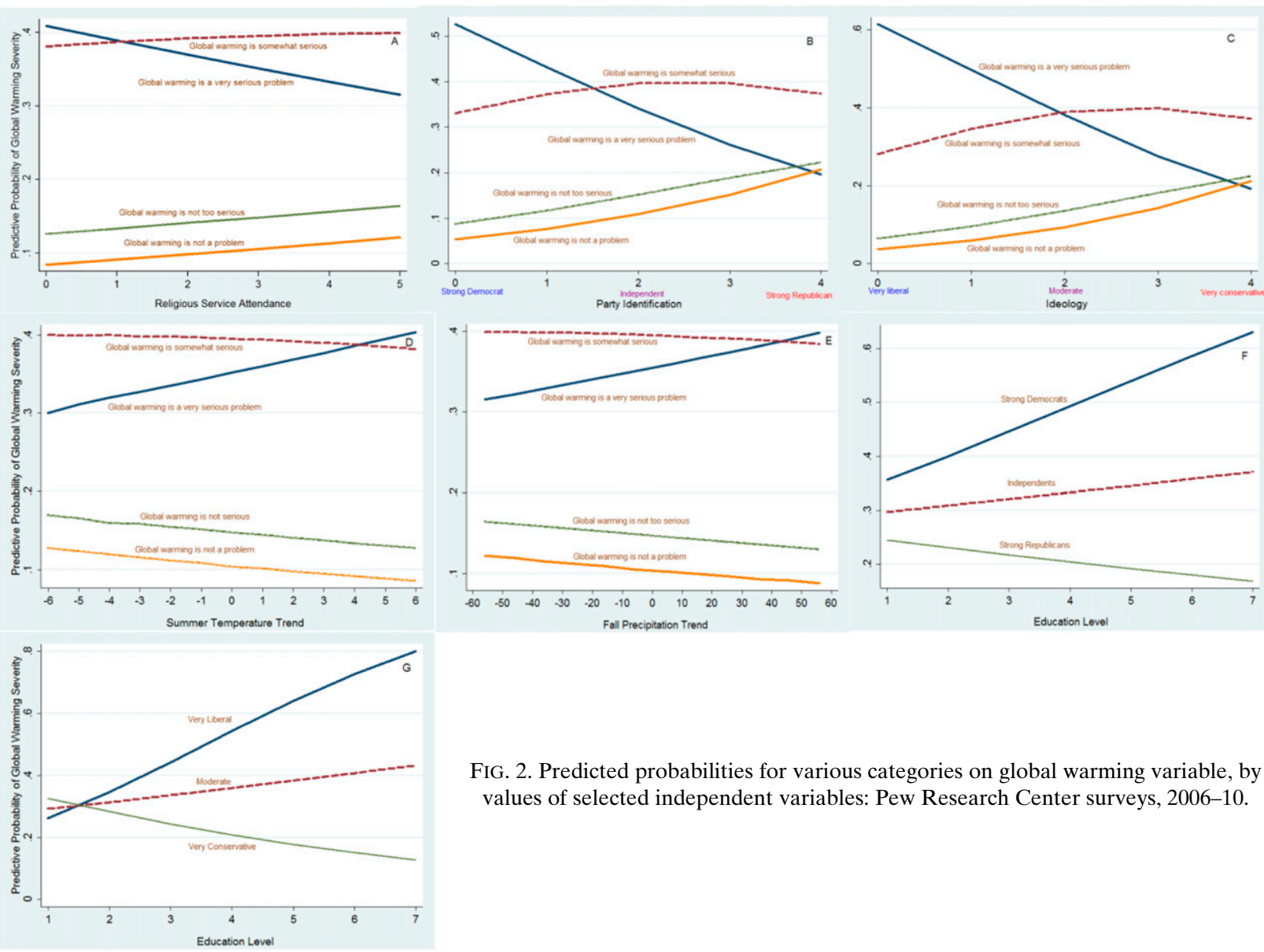

FIG. 2. Predicted probabilities for various categories on global warming variable, by values of selected independent variables: Pew Research Center surveys, 2006-10.

global warming severity. Specifically, women, blacks, and Hispanics are more likely to view global warming as a very serious problem than their counterparts. The coefficient for age demonstrates that younger people are more likely than older people to perceive that global warming is a serious problem. Education and income also affect perceptions of global warming, although in opposite directions. Education is positively associated with global warming severity; individuals with higher education levels are more likely to accept the severity of global warming as a problem. On the other hand, income depresses perceptions of global warming severity, with high income earners less likely to perceive the severity of global warming. These findings are consistent with both theoretical expectations and the findings based on our analyses of the CBS News/New York Times data.

Religious service attendance has a significant and negative effect on global warming severity. This suggests that individuals who attend religious services more often are more likely to doubt the severity of global warming. Based on the predicted probabilities from Fig. 2a, the probability that people who attend religious services more than once a week believe that "global warming is a somewhat serious problem" is $40 \%$, compared to $38 \%$ for people who never attend religious services. On the other hand, by a margin of $41 \%-32 \%$ people who never attend any religious services are more likely to believe that "global warming is a very serious problem" than those who attend religious services more than once a week.

Party identification and political ideology both have significant and negative effects on global warming severity, indicating that Republicans and conservatives are less likely than Democrats and liberals to think that global warming is a very serious problem. Using results from Table 3, model 1 for Pew survey series, in Fig. 2b, we show the predicted probabilities for the relationships between party identification and perception of global warming severity, holding all other independent variables constant at their means. For the statement "global warming is a very serious problem," the probability that Democrats agree with this is $53 \%$, compared to $20 \%$ for Republicans. On the other hand, Republicans (37\%) are 
slightly more likely to believe "global warming is somewhat serious" than Democrats (33\%). The probability of believing that "global warming is not a problem" increases from $5 \%$ to $21 \%$ as one moves from "Democrat" to "Republican" on the partisanship scale. Likewise, political ideology has a similar effect on global warming severity. As Fig. 2c demonstrates, as individuals move from "liberal" to "conservative" the probability that they believe that "global warming is a very serious problem" decreases by $42 \%$, while the probability for they believe that "global warming is not a problem" increases by $17 \%$.

Similar to our findings of the CBS News/New York Times data, we find that unemployment at the county level does not have a significant effect on public risk perception of global warming severity. This again reflects the limited power of objective macroeconomic measures to explain public perceptions of global warming.

Among the local weather and climate measures, summer temperature trends and fall precipitation trends over the past 10 years stand out as significant predictors of global warming severity. Specifically, individuals who have experienced increasingly hot summers over the past 10 years are more likely to accept that "global warming is a very serious problem." To illustrate the effects of this local climate indicator in Fig. 2d, we present the predicted probabilities for the relationship between summer temperature trend and our four outcomes relating to perceptions of global warming severity, controlling for the effects of all other independent variables. As the trend in local temperatures increases from a low of approximately -6 to a high of approximately +6 , the probability that one thinks that "global warming is a very serious problem" increases from $30 \%$ to $40 \%$, while the probability that one believes that "global warming is not a problem" decreases from $13 \%$ to $9 \%$. Furthermore, individuals who have experienced increasing precipitation during the fall season over the past 10 years tend to believe that "global warming is a very serious problem." In Fig. $2 \mathrm{e}$, the predicted probabilities for the relationship between this climate measure and the four perceptions of global warming severity are shown. As the indicator for one's experience with precipitation during the fall moves from its minimum $(-56)$ to its maximum $(+56)$, the probability that one thinks that "global warming is a very serious problem" increases from $32 \%$ to $40 \%$, while the probability that one believes that "global warming is not a problem" decreases from $12 \%$ to $9 \%$. It is interesting to note that the fall precipitation has shown the greatest variability across the conterminous United States over the past 92 yr (De Martino et al. 2013), which may be a contributing factor in these perceptions.
In models 2 and 3 of Table 3 for the Pew survey series, we include two interaction variables, one for education and party identification and the other for political ideology and education, respectively. Both interaction terms have coefficients that are statistically significant and negative, indicating that education has different effects on public risk perception of global warming severity among Republicans and Democrats, on the one hand, and conservatives and liberals, on the other. Turning first to model 2 results for the Pew survey series, we find that the coefficient for education is positive and highly significant ( $b=0.189, Z=8.35$ ); this suggests that for Democrats (i.e., those who score 0 on the partisanship scale) there is a strong positive relationship between education and the perception that global warming is a severe problem.

Furthermore, the coefficient in model 2 for Pew survey series of the interaction for party identification and education is negative and highly significant $(b=-0.067$, $Z=-8.15$ ), indicating that the effects of education on the log-odds ratio of the dependent variable decreases by 0.067 as party identification increases by one unit (moving from Democratic identification toward Republican identification). Accounting for both the education and interaction coefficients, we estimate the education coefficient for Republicans to be -0.079 [i.e., $0.189+(4 \times-0.067)]$, indicating that for Republicans the effects of education on global warming severity is moderately negative. To illustrate, in Fig. $2 \mathrm{f}$ we present predicted probabilities for the relationship between education level and individuals' perceptions that "global warming is a very serious problem," broken down by strong Democrats, independents, and strong Republicans and holding all other independent variables constant at their means. For strong Democrats with low education (i.e., $0-8$ grades completed), the probability that they perceive "global warming is a very serious problem" is $35.6 \%$; this rises to a probability of $63.1 \%$ for strong Democrats with high education level (i.e., postgraduate work or degree). On the other hand, the effect of education on perceptions of global warming severity among strong Republicans is moderate; the probability of perceiving that "global warming is a very serious problem" decreases from $24.5 \%$ percent to $16.9 \%$ as the education level moves from its lowest to highest value. Clearly, there is a strong difference in how Democrats and Republicans translate education into perceptions of global warming severity.

For model 3 for the Pew survey series, the coefficient for education ( $b=0.398, Z=9.73)$ is once again positive and highly significant, indicating that among strong liberals increases in education result in perceptions of global warming severity. Meanwhile, the coefficient for 
the interaction for political ideology in model 3 for the Pew survey series is also negative and significant $(b=$ $-0.148, Z=-9.00)$, and this suggests that the effect of education on the log-odds ratio of global warming severity decreases by 0.148 as political ideology increases by one unit (i.e., as one moves in the conservative direction). This finding conforms to results in the first study of this paper. What this means is that the coefficient for education on global warming severity among strong conservatives is $-0.195[0.398+(4 \times$ $-0.148)$ ] and significant, suggesting that the increase of education suppresses perceptions of global warming severity among conservatives. Similarly, as Fig. $2 \mathrm{~g}$ demonstrates, the effects of education on public perception of global warming severity vary significantly over the spectrum of political ideology. For strong liberals, the probability that they perceive "global warming is a very serious problem" increases from $26.1 \%$ to $79.9 \%$ as one increases the level of education. On the other hand, education has a negative effect on public perception of global warming among strong conservatives. The probability that one perceives that "global warming is a very serious problem" decreases from $32.6 \%$ to $12.7 \%$ as one decreases the level of education.

\section{Conclusions}

In this paper we investigate how sociodemographic characteristics, political orientations, local weather and climate, and unemployment affect public perceptions of global warming. This task is accomplished by utilizing two series of survey data and from two pooled crosssectional datasets. The CBS News/New York Times series includes a question that addresses issues of global warming immediacy (i.e., are the risks of global evident in our proximate future or in our distant future?), while in contrast the Pew survey series addresses issues involving global warming severity (i.e., is global warming a problem and if so, how severe a problem is it?). We speculate that these two dimensions are related, insofar as individuals who perceive that global warming is a serious and immediate problem are likely to be the most motivated to support actions to alleviate potential impacts of climate change.

What have we learned here? First, perhaps our most important findings relate to the effects of weather and climate contexts on how Americans think about global warming. We consider in our pooled models the effects of 10-yr temperature and precipitation trends for each of the four seasons, as well as short-term temperature and precipitation fluctuations, and it is interesting to note that most of our coefficients for these variables fail to achieve conventional levels of statistical significance.
There are two exceptions among the local weather and climate measures. Most noteworthy is the 10 -yr summer temperature trend, which is found to have a strong positive effect on both global warming immediacy (CBS News/New York Times data) and global warming severity (Pew data). We find that winter, spring, and fall temperature trends do not have systematic effects on global warming attitudes, but it appears that individuals who reside in communities with increasingly hot summers are significantly more likely to perceive global warming immediacy and severity than those residing in communities with flat or cooling trends. What this suggests is that actual climate changes play an important role in shaping public perceptions of global warming. Changes in summer temperatures are recent enough to be remembered but are of long enough duration to be salient, and hence these patterns of warming temperatures affect significantly how individuals think about climate change. Certainly one important take-away message from this study is that local climate conditions represented by summer temperature trends over a $10-\mathrm{yr}$ time period can have a discernible effect on attitudes relating to the immediacy and severity of global warming. Second, while precipitation trends typically do not have a systematic effect on attitudes toward global warming, there is some evidence in the Pew data that fall precipitation trends have a positive effect on perceptions of global warming severity. In two of our models fall precipitation trends have moderate (but significant) effects, and in a third model the effect just misses conventional levels of statistical significance. We suggest that more research is needed on the effects of precipitation on individuals' perceptions of global warming. Another important frontier is national-scale analysis that can distinguish weather/climate effects from geographical differences, by including geographic indicators in the models: for example, through mixed-effects modeling (Hamilton and Keim 2009).

Second, we also confirm that sociodemographic variables have strong significant effects on public perceptions of global warming over the past decade. Specifically, young people, women, and racial minorities (including African Americans and Hispanics) are more likely to show a higher level of concern for global warming than their counterparts. On the other hand, individuals with higher levels of income are less likely to express concern about global warming; this may reflect a self-interest motive, whereby higher-income individuals are resistant to concerns about climate change because they may perceive that they would be most likely to pay higher taxes to support the environmental programs needed to alleviate global warming. We also find a direct positive effect of education on 
concerns with global warming; those with higher levels of education tend to perceive global warming as an immediate and severe threat, perhaps because they are more likely to be exposed to scientific information about global warming.

Third, political orientations have consistently strong effects in terms of how the public views the immediacy and severity of global warming. Democrats and liberals are more likely than Republicans and conservatives to express concerns about the immediacy and severity of global warming. Furthermore, we find that the relationship between education and public perceptions of global warming is moderated by both partisanship and ideology. As education increases, Democrats and liberals are more likely to see the immediacy and severity of global warming. However, the same pattern does not hold true for Republicans and conservatives; as education increases for these groups, views toward the immediacy and severity of global warming become weaker. We speculate that political dispositions serve as an information filter, with Democrats and liberals more likely to accept information about global warming while Republicans and conservatives are more resistant to this information. These results contribute more evidence to the accumulating literature on the polarizing effects of education along partisan and ideological lines (Hamilton 2008, 2011; Hamilton and Keim 2009; McCright and Dunlap 2011a). We therefore replicate an important interaction effect using extensive data collected over a longer time frame.

Finally, the unemployment rate in respondents' local communities is not found to have any significant effects on public risk perceptions of global warming, in contrast to findings by Hamilton et al. (2010) regarding other types of environmental concern. The difference between our results and those of Hamilton et al. is a bit inexplicable, although we note a difference in sampling frame-that is, we use a national sample including urban, suburban, and rural areas while Hamilton et al. focus on respondents from rural areas in a selected group of states - that may possibly account for the differences in our two sets of results. Our result also suggests that future studies examining the effects of the economy on public risk perception of global warming should adopt measures to represent personal objective economic conditions or individuals' subjective assessments of those economic conditions. Objective economic conditions do not necessarily translate into subjective judgments on the economy, and future studies should be directed to include variables that measure the subjective judgment of the economy.

Acknowledgments. Wanyun Shao is a recent Ph.D. graduate from Department of Geography and Anthro- pology at Louisiana State University. Her current affiliation is the Louisiana Coastal Protection and Restoration Authority. Barry D. Keim is the Fred B. Kniffen Professor of Geography, Louisiana State Climatologist, and Director of NOAA's Southern Climate Impacts Planning Program at Louisiana State University. James C. Garand is the Emogine Pliner Distinguished Professor and R. Downs Poindexter Professor of Political Science at Louisiana State University. Lawrence C. Hamilton is the Professor of Sociology and a Senior Fellow of the Carsey Institute at the University of New Hampshire. This paper is based on research supported by NOAA Grant NA080AR4320886. The findings and opinions reported are those of the authors and are not necessarily endorsed by the funding organizations.

\section{REFERENCES}

Borick, C. P., and B. G. Rabe, 2010: A reason to believe: Examining the factors that determine individual views on global warming. Soc. Sci. Quart., 91, 777-800.

De Martino, G., N. Fontana, G. Marini, and V. P. Singh, 2013: Variability and trend in seasonal precipitation in the continental United States. J. Hydrol. Eng., 18 (6), 630-640.

Dunlap, R. E., and A. M. McCright, 2008: A widening gap: Republican and Democratic views on climate change. Environment, 50, 26-35.

, C. Xiao, and A. M. McCright, 2001: Politics and environment in America: Partisan and ideological cleavages in public support for environmentalism. Environ. Polit., 10 (4), $23-48$.

Egan, P. J., and M. Mullin, 2012: Turning personal experience into political attitudes: The effect of local weather on Americans' perceptions about global warming. J. Polit., 74 (3), 796-809.

Elliott, E., B. J. Seldon, and J. L. Regens, 1997: Political and economic determinants of individuals' support for environmental spending. J. Environ. Manage., 51, 15-27.

Finucane, M. L., P. Slovic, C. K. Mertz, J. Flynn, and T. A. Satterfield, 2000: Gender, race, and perceived risk: The 'white male' effect. Health Risk Soc., 2 (2), 159-172.

Hamilton, L. C., 2008: Who cares about polar regions? Results from a survey of U.S. public opinion. Arct. Antarct. Alp. Res., 40, 671-678.

- 2011: Education, politics and opinions about climate change evidence for interaction effects. Climatic Change, 104, 231242.

- 2012: Did the Arctic ice recover? Demographics of true and false climate facts. Wea. Climate Soc., 4, 236-249.

— about climate change. Int. J. Climatol., 29, 2348-2352.

— , and M. D. Stampone, 2013: Blowin' in the wind: Short-term weather and belief in anthropogenic climate change. Wea. Climate Soc., 5, 112-119.

— C. R. Colocousis, and C. M. Duncan, 2010: Place effects on environmental views. Rural Sociol., 75, 326-347.

Howe, P., E. Markowitz, T. M. Lee, C. Y. Ko, and A. Leiserowitz, 2013: Global perceptions of local temperature change. Nat. Climate Change, 3, 352-356, doi:10.1038/nclimate1768. 
Kahn, M. E., and M. J. Kotchen, 2010: Environmental concern and the business cycle: The chilling effect of recession. National Bureau of Economic Research (NBER) Working Paper 16241, 28 pp.

Karl, T. R., C. N. Williams Jr., F. T. Quinlan, and T. A. Boden, 1990: United States Historical Climatology Network (HCN) serial temperature and precipitation data. Environmental Science Division Publ. 3404, Carbon Dioxide Information and Analysis Center, Oak Ridge National Laboratory, $389 \mathrm{pp}$

Kellstedt, P. M., S. Zahran, and A. Vedlitz, 2008: Personal efficacy, the information environment, and attitudes toward global warming and climate change in the United States. Risk Anal., 28, 113-126.

Krosnick, J. A., A. L. Holbrook, L. Lowe, and P. S. Visser, 2006: The origins and consequences of democratic citizens' policy agendas: A study of popular concern about global warming. Climatic Change, 77, 7-43.

Leiserowitz, A., 2006: Climate change risk perception and policy preferences: The role of affect, imagery, and values. Climatic Change, 77, 45-72.

, E. Maibach, C. Roser-Renouf, G. Feinberg, and P. Howe, 2012: Extreme weather and climate change in the American mind. Yale University and George Mason University Rep., 30 pp.

Li, Y., E. J. Johnson, and L. Zaval, 2011: Local warming: Daily temperature change influences belief in global warming. Psychol. Sci., 22 (4), 454-459.

Malka, A., J. A. Krosnick, and G. Langer, 2009: The association of knowledge with concern about global warming: Trusted information sources shape public thinking. Risk Anal., 29, 633-647.

Marshall, B. K., 2004: Gender, race, and perceived environmental risk: The "white male effect" in Cancer Alley, LA. Sociol. Spectrum, 24, 453-478.

Maslow, A. H., 1943: A theory of human motivation. Psychol. Rev., 50, 370-396.

McCarthy, J. J., and Coauthors, Eds., 2001: Climate Change 2001Impacts, Adaptation and Vulnerability. Cambridge University Press, 1032 pp.
McCright, A. M., 2009: The social bases of climate change knowledge, concern, and policy support in the U.S. general public. Hofstra Law Rev., 37, 1017-1046.

— , and R. E. Dunlap, 2011a: The politicization of climate change and polarization in the American public's views of global warming, 2001-2010. Sociol. Quart., 52, 155-194.

— and - 2011b: Cool dudes: The denial of climate change among conservative white males in the United States. Global Environ. Change, 21, 1163-1172.

Myers, T., E. Maibach, C. Roser-Renouf, K. Akerlof, and A. Leiserowitz, 2013: The relationship between personal experience and belief in the reality of global warming. Nat. Climate Change, 3, 343-347, doi:10.1038/nclimate1754.

Nisbet, M. C., and T. Myers, 2007: Twenty years of public opinion about global warming. Public Opin. Quart., 71, 444-470.

Parry, M. L., O. F. Canziani, J. P. Palutikof, P. J. van der Linden and C. E. Hanson, Eds., 2007: Climate Change 2007-Impacts, Adaptation and Vulnerability. Cambridge University Press, 976 pp.

Pew Research Center, cited 2006: Little consensus on global warming: Partisanship drives opinion. [Available online at http://people-press.org/reports/display.php3?ReportID=280.]

_ [Available online at http://people-press.org/reports/pdf/303. pdf.]

_ - cited 2012: More say there is solid evidence of global warming. [Available online at http://www.people-press.org/2012/10/ 15/more-say-there-is-solid-evidence-of-global-warming/.]

Primo, D. M., M. L. Jacobsmeier, and J. Milyo, 2007: Estimating the impact of state policies and institutions with mixed-level data. State Polit. Policy Quart., 7, 446-459.

Rabe-Hesketh, S., and A. Skrondal, 2008: Multilevel and Longitudinal Modeling Using Stata. 2nd ed. Stata Press, $562 \mathrm{pp}$.

Tegart, W. J. McG., G. W. Sheldon, and D. C. Griffiths, Eds., 1990: Climate Change 1990-The IPCC Impacts Assessment. Australian Government Publishing Service, $294 \mathrm{pp}$.

Watson, R. T., M. C. Zinyowera, and R. H. Moss, 1995: Climate Change 1995-Impacts, Adaptations and Mitigation of Climate Change: Scientific-Technical Analyses. Cambridge University Press, 878 pp. 